\title{
Possíveis leituras do conto $O$ visto, de Ondina Ferreira
}

\author{
Mariana Andrade Gomes ${ }^{1}$
}

RESUMO: Este texto tem como objeto de análise a breve narrativa ficcional O Visto", cujo enredo decorre no século XXI e trata da história de uma mulher da Ilha do Fogo. A partir da tentativa de Dona Victória de retirar o Visto para os Estados Unidos, pretendo analisar aqui as formas com as quais a potência subversora do riso pode ser utilizada para operacionalizar discursos de resistências/persistências entre Cabo Verde e os novos (EUA) e velhos (Portugal) centros de poder.

ABSTRACT: This text has as its object of analysis the short fictional narrative held in the twenty-first century about a woman from the Ilha do Fogo in Cape Verde. From the attempt to get the visa for the United States by Dona Victória, I intend to analyze the ways in wich the subversive power of laugher can be used to operationalize speeches of resistance/persistence between Cape Verde and the new (US) and old (Portugal) Power centers.

PALAVRAS-CHAVE: Cabo Verde; Narrativas; Riso; Discursos; Poder. KEYWORDS: Cape Verde; Narratives; Laugh; Speeches; Power.

\section{"Qual o motivo da sua viagem?"}

Dona Victória Maria Barbosa Avelino Medina do Sacramento Teixeira é - como o extenso sobrenome já indica - uma filha "da gente de Sobrado", antiga elite de Cabo Verde afastada do poder com a Independência do arquipélago em 1974. “Olhe, quando o 25 de Abril [Revolução dos Cravos] chegou aqui, as coisas transtornaram-se de uma tal maneira, que já ninguém conhecia o seu lugar na sociedade e tudo saiu fora do lugar" (FERREIRA, 2010, p. 179). "Sofrendo" as consequências da nova ordem², a família de D. Victória perde suas posses, entrando em uma crise tanto econômica quanto social, ainda agravada pela reforma agrária - chamada de "afronta agrária" por seu pai. Para não perder o sobrado, sua herança secular, a protagonista aceita se casar, aos quarenta e um anos, com João Teixeira, neto do feitor de seu avô materno.

João Teixeira reside nos Estados Unidos e, com o dinheiro que conseguiu trabalhando em uma fábrica, comprou algumas terras e o sobrado, último espólio da antiga família de renome tanto na ilha quanto na velha metrópole. No acordo firmado com seu marido - o que sinaliza uma união de conveniência não desejada por D. Victória

\footnotetext{
${ }^{1}$ Doutoranda do Programa de Literatura e Cultura da Universidade Federal da Bahia (PPGLitCult). Desenvolve a pesquisa temporariamente intitulada "O riso político na ficção de Cabo Verde pósindependência", financiada pela Fundação de amparo à pesquisa do Estado da Bahia - FAPESB.

${ }^{2}$ A “nova ordem", neste caso, refere-se à Revolução dos Cravos ou Revolução de 25 de abril, ocorrida em 1974 em Portugal, na qual o regime ditatorial do Estado Novo foi deposto, iniciando a redemocratização no país. No caso cabo-verdiano, esse evento, em conjunto com a Independência em 5 de julho de 1975, enfraqueceu as antigas elites dominantes associadas à ex-metrópole.
}

Revista Crioula USP, $\mathrm{n}^{\circ}$ 17, junho de2016 
-, uma visita seria feita em dezembro, com prazo até janeiro, sendo necessária a aquisição de um visto temporário a ser retirado na Embaixada dos Estados Unidos na cidade da Praia.

A trama ficcional, então, desencadeia-se pela incompreensão do cônsul em "reconhecer" os motivos pelos quais a protagonista não deseja morar nos Estados Unidos com seu marido - principal destino de cabo-verdianas e cabo-verdianos na procura por melhores condições de trabalho e econômicas. Tal indagação se pontua, inclusive, no subtítulo desta seção, por meio de uma das falas extraídas do conto em que o cônsul interpela Dona Victória sobre qual seria a finalidade de sua viagem - um ponto já abordado no formulário ${ }^{3}$ de solicitação do visto e que dispensaria maiores discussões se o representante estadunidense não desconfiasse das intenções da protagonista. É isto, juntamente com a falta de um atendimento especial por parte da Embaixada, que tanto incomoda Dona Victória: ser equiparada a essa "gentinha pobre” (Ibidem, p. 178).

\section{Possíveis leituras: o riso de dois gumes e alguns apontamentos sócio-históricos}

O temperamento forte e uma certa arrogância risível expressa por Dona Victória neste conto podem ser interpretados, à primeira vista, como uma forma de crítica aos costumes da antiga elite de "filhos da terra" da qual a personagem faz parte. Esse termo é utilizado por teóricos para demarcar as pessoas nascidas em Cabo Verde cujas heranças portuguesas concediam privilégios no arquipélago, regalias oriundas do início da colonização, nos tempos de povoamento das ilhas.

João Lopes Filho (1983, p. 12) destaca que o Infante D. Fernando recebeu "privilégios especiais" para propiciar a ocupação das terras, visto que "a colonização daquele arquipélago, inteiramente despovoado e a tão grande distância da metrópole exigia grandes incentivos" ${ }^{\prime}$. Entre os benefícios concedidos pela coroa portuguesa aos colonos cabo-verdianos, destaca-se a autonomia que os donatários (mais especificamente da Ilha de Santiago) receberam para negociação, venda e apreensão de escravizados da Costa da Guiné, bem como o comércio de produtos agrícolas, dentre outros, advindos deste mesmo local, sendo o arquipélago um importante entreposto comercial para a metrópole e outros países.

\footnotetext{
${ }^{3}$ Conforme assinala a personagem principal, Dona Victória.

${ }^{4}$ Outro termo que apresenta alguma equivalência e que também aparece na historiografia e nas teorias sobre a mestiçagem em Cabo Verde é "brancos da terra" (cf. Lopes Filho, 1983).

${ }^{5}$ Jaime Cortesão, 1975, p. 667, apud Lopes Filho, 1983, p. 16.

Revista Crioula USP, $\mathrm{n}^{\circ}$ 17, junho de2016
} 
Luís Batalha (2004) lança mão do termo "elite portuguesa-cabo-verdiana" para designar este grupo "intermediário colonial” de funcionários administrativos das colônias ou províncias ultramarinas. Ao adotar esta expressão, o autor descarta a palavra composta "luso-cabo-verdiano", para assinalar que, além desta palavra ser fruto de uma demanda recente dos tempos pós-coloniais ${ }^{6}$, o termo "português" reflete mais especificamente a autorrepresentação daqueles que se compreendem enquanto portugueses nascidos em Cabo Verde (mas residentes em Portugal mesmo depois da Independência), sendo este uma extensão de Portugal e a identificação cabo-verdiana um complemento de sua identidade principal portuguesa. Batalha (2004) pontua, ainda, que a palavra "elite" deve ser utilizada entre aspas porque, apesar desta auto-inscrição, tal status nunca lhe foi atribuído, tanto nos tempos coloniais quanto na contemporaneidade. Todavia, cabe o questionamento acerca da refutação do status dessa elite que, possivelmente, deveria gozar de certos privilégios nas ilhas e ter uma condição financeira mais elevada que a média da população cabo-verdiana.

Com o advento da Independência, em 1975, os símbolos que se identificavam com a ex-metrópole foram rechaçados e as classes que representavam o antigo poder se tornaram alvo de ridicularização, daí ser possível uma primeira leitura da personagem, que reproduzia ideologias tipicamente coloniais classistas, racialistas, individualistas e nacionais-portuguesas.

Em Cabo Verde, assim como em muitos países sob a sombra da colonização, a Literatura foi utilizada como ferramenta para propagação de ideais, fosse para legitimar ou questionar os poderes vigentes. Nesse sentido, Gabriel Fernandes (2002) propõe uma racionalização identitária, tendo como marco inaugural a geração que formulou a Revista Claridade $^{7}$ analisada a partir de dois parâmetros de categorização; um que compreendia o "componente afro-negro da cultura cabo-verdiana como mera sobrevivência do passado", logo, em vias de extinção; e outro que idealizava Cabo Verde como uma região de Portugal que adotava a identidade mestiça enquanto sua (Ibidem, p. 81).

Fernandes (Ibidem) afirma que a geração claridosa, predecessora da geração de nativistas $^{8}$, foi crucial para a elaboração de uma mestiçagem não mais vista como "raça

\footnotetext{
${ }^{6} \mathrm{O}$ termo pós-colonial, neste caso, assume a conotação cronológica, assinalando o período posterior às Independências.

${ }^{7}$ Revista fundada na cidade de Mindelo e publicada entre 1936 e 1966. Anjos (2006, p. 148) assinala que a formação dos componentes da Claridade se deu em Lisboa, nas décadas de 1920 e 1930, no auge do movimento modernista e em contraposição à vertente romântico-clássica.

${ }^{8}$ Embora esta geração não tenha colocado a questão do mestiço, o processo de identificação era feito através da proximidade ou da distância em relação à metrópole.
}

Revista Crioula USP, $\mathrm{n}^{\circ}$ 17, junho de2016 
mista" e desprezada, passando a adquirir um caráter de "raça cósmica" designando "o que de melhor havia nos dois mundos [europeu e africano ou europeu e cabo-verdiano?]: uma síntese perfeita em termos raciais e culturais" (Ibidem). Tal valoração do mestiço fundamentou-se, principalmente, no lusotropicalismo de Gilberto Freyre, o qual, por sua vez, estava apoiado pelo poder colonial. Ainda conforme Fernandes (Ibidem), o Congresso de Sociologia Colonial de Paris em 1900 estabeleceu a “[...] equiparação do mestiço ao elemento europeu, levando a um relativo esvaziamento das ideologias racistas (então prevalecentes nos Estados Unidos e na Europa), segundo as quais a mistura das raças tinha um efeito degenerativo sobre os povos".

Nota-se, então, a valoração positiva que a proximidade com a metrópole/Europa possui na configuração identitária do mestiço, bem como o processo de elaboração de uma "nova hegemonia"10, empreendida pelos claridosos/brancos da terra. Segundo o sociólogo, essa elite intelectual construiu a questão do branqueamento social em termos culturais/civilizacionais em detrimento da perspectiva econômica/legal como um recurso para erigir a mestiçagem enquanto traço peculiar da cultura cabo-verdiana, tendo em vista seu projeto político-emancipatório. Tal construção identitária é tão emblemática para este plano independentista que Gabriel Fernandes (Ibidem, p. 90) chega a asseverar que a geração da Claridade construiu uma identidade mestiça quando pensavam explicá-la.

Retornando ao conto de Ondina Ferreira, é por meio da reivindicação de seus privilégios que Dona Victória, enquanto integrante de uma família tradicional aristocrática, exige a legitimação/sobreposição desta identidade/status perante o nãoreconhecimento da autoridade do cônsul. A protagonista procede desta maneira motivada tanto pelo menosprezo da condição de emigrado do marido, quanto pela superior representatividade dos EUA no cenário internacional, em relação a Portugal. São esses os aspectos que possibilitam uma das chaves analíticas deste conto: o riso presente na narrativa não aparece direcionado às críticas ao antigo poder, mas, sim, à nova ordem vigente, representada pelas figuras dos Estados Unidos e do sistema governamental que se consolidou a partir da Independência.

Desde o início do conto, a personagem se mostra incomodada com o atendimento pouco "pessoal” concedido a ela pela Embaixada dos EUA. Dona Victória acreditava que seria recebida exclusivamente pelo cônsul ou por algum funcionário específico designado para a obtenção de seu visto. Sua consternação advém, então, da constatação de que seria

\footnotetext{
${ }^{9}$ Stavenhagen, 1993, p. 65, apud Fernandes, 2002, p. 81.

${ }^{10}$ Para citar novamente Fernandes (Ibidem, p. 82).

Revista Crioula USP, $\mathrm{n}^{\circ}$ 17, junho de2016
} 
submetida ao mesmo tratamento de outros interessados: teria que passar pela sala de espera até a entrevista com o cônsul, seria chamada pelos alto-falantes e sua conversa seria difundida por alto-falantes, espalhados neste ambiente, de forma escancarada. Algo diversamente distante do modelo reservado que ela supunha para o recebimento de uma pessoa de "estirpe". Tal atitude representou uma ameaça para a senhora, fazendo-a pensar em desistir: "Apeteceu-lhe desistir. Sair e ir telefonar ao marido comunicando-lhe a intenção. Cheirou-lhe a algum tipo de intimidação ou mesmo de humilhação, aquele aparato. Faria parte da pouca consideração que o país do dólar nutria pelos outros?” (FERREIRA, 2010, p. 173).

Pode-se interpretar a indignação de Dona Victória como reação tanto à desconsideração da Embaixada por uma pessoa de sua "classe", quanto à burocracia/vigilância extremadas para aquisição do visto, em um gesto que, enquanto supervaloriza a viagem para o país ao dificultar este processo, também rebaixa a nação e seus habitantes em seu demasiado esforço e no aviltamento de sua imagem ao colocá-los como alvos de suspeita, tamanha são as medidas de segurança envolvidas.

Outro fator que provocou intensa revolta em Dona Victória foi a desconfiança do cônsul sobre o período de permanência nos Estados Unidos. Ele a questiona:

Bem, continuando, a senhora Victória ainda não me disse os verdadeiros motivos que a levam... Tem estado até agora a... desculpe a franqueza, a divagar. O que quero saber é a garantia que me dá para eu acreditar no seu regresso. Está a ver: é a primeira vez que vai estar com ele. O seu marido vive e trabalha lá. Ele tem casa lá. Como garante que sua intenção não é ir para ficar? E pede um Visto de Turista? Não há-de estar a tentar enganar a Embaixada, pois não, senhora Victória? (Ibidem, p. 176).

Dona Victória tentava expor os fatos que acreditava serem motivos suficientes para garantir seu retorno à Ilha no tempo estipulado. Todavia, as justificativas apresentadas não satisfaziam o indiferente funcionário, pois, como afirmava a personagem, seu embasamento era culturalmente e socialmente diverso das vivências do cônsul. Sua situação de "relevo" na Ilha não lhe forçava a emigrar como acontecia com boa parte de cabo-verdianos e cabo-verdianas que viajavam para atingir um melhor nível de poder aquisitivo, como citado anteriormente. Compará-la com pessoas nesta circunstância a incomodava profundamente, posto que pôs em dúvida seus propósitos:

[...] Oh senhor Cônsul, eu não pretendo enganar ninguém e nem tenho necessidade de fazer tal coisa. Vamos aqui clarificar alguns pontos que 
me parecem não estar bem entendidos. Eu, quando pedi visto de turista era, é, e continua a ser mesmo este o tipo de entrada que pretendia, e pretendo. Ponto final, parágrafo. O senhor está-me a entender! Fala bom português, portanto vai entender tudo. Tenho quarenta e um anos de idade. Venho de família antiga. Abastada noutros tempos e com nome conhecido na ilha. Casei tarde porque quis. Podia ter casado em tempo certo. Pretendentes não me faltaram. Escolhi muito e fui perdendo as oportunidades em matéria de arranjar marido à altura. Só agora, há coisa de um ano, achei por bem fazê-lo... [...] Nunca, em tempo algum, passou-me pela ideia de emigrar para lá. Porquê? Por várias razões, das quais só posso explicar aquelas que me são familiar e culturalmente explicáveis. [...] (Ibidem, p. 177).

Possivelmente, o cônsul não entenderia as razões de Dona Victória por generalizar as intenções das pessoas que o procuram para conseguir o tão almejado documento. Dona Victória explica que este tipo de viagem não é o destino de pessoas "de sua classe":

\begin{abstract}
Nasci num sobrado. Espero que entenda isto. Habituei-me, do tempo do meu avô paterno a vê-lo, e posteriormente aos meus pais, a tratar de papéis para os guardas das propriedades de café e empregados das lojas que tínhamos, ou seus familiares. Desde atestado médico, passando pelo preenchimento dos formulários da vossa Embaixada, indo até tratar da situação militar, dado que eram os homens que na altura saíam à procura de vida melhor na terra do senhor cônsul. Por vezes, chegavam mesmo a abonar-lhes ou a pagar-lhes a passagem. Mas nunca nós. Eles sim. Então eu levantei-me com o entendimento que ir para lá era para quem estava necessitado. Como se dizia antigamente, para gentinha pobre. Bem, também é verdade que havia algumas exceções dentro das famílias da alta. Um ou outro membro, normalmente por razões de desavença familiar, ou de empobrecimento inesperado, lá zarpava para a sua terra, senhor Cônsul. Era um tipo de viagem que a nós não prestigiava. Nós íamos para Lisboa. Ah! Sim! Essa era a viagem prestigiante para gente como nós! Ou passear, passar temporadas, ou consulta médica, ou ir lá frequentar colégios... ou assim. Eu por acaso não fui. Filha "codê ${ }^{11}$ ", não me queria separar da minha mãe. Mas os meus irmãos, quase todos. Sobretudo os rapazes. Olhe, dois deles passaram lá alguns anos. É certo que não aproveitaram bem os estudos e até gastaram nisso muito dinheiro ao nosso pai, mas regressaram a tocar muito bem violino e bandolim. Eu, muito apegada à minha mãe e às coisas da casa, fui tomando conta de tudo. No fim, já adulta e única solteira, era quem cuidava dos bens da família. Sempre vivi em S. Filipe e espero que os meus ossos lá fiquem quando chegar a hora (Ibidem, p. 178-179).
\end{abstract}

Ao se explicar, Dona Victória provavelmente tinha conhecimento de que, enquanto era entrevistada pelo cônsul, sua conversa era transmitida para a sala de espera e tanto o funcionário quanto as outras pessoas seriam informadas de sua "elevada

\footnotetext{
${ }^{11}$ Termo cuja acepção designa as filhas caçulas, filhas mais novas dentre as filhas ou filhos.
} 
condição social". Tal postura se apresenta ao longo do texto também expressa pelo não uso do crioulo cabo-verdiano, língua ainda não-oficial mas falada, inclusive, em esferas públicas como escolas, juizados, entre outros. Ainda assim, observa-se que a língua portuguesa continua sendo símbolo de distinção, podendo-se compreender a colocação de Dona Victória por esse viés (“Fala bom português, portanto vai entender tudo.”).

Provavelmente, tais atitudes pretensiosas representavam uma dupla maneira de se firmar, demonstrando que não precisava desta autorização como as outras pessoas, por isso, não precisaria se "sujeitar" àquele tratamento indiferente e mecânico. Além de explicitar que não precisaria recorrer a esta viagem para conseguir se manter, seguindo o padrão de algumas mulheres que, de acordo com Iolanda Évora e Marzia Grassi (apud SHELDON; FÊO, 2008, p. 437-438), emigram para os Estados Unidos para trabalhar como domésticas ou babás. Condição que, para a personagem, não é "típica” de pessoas de sua "classe".

Devido à grande quantidade de interessados, o atendimento deveria ser o mais breve possível, o que o tornou automático e distante para que, teoricamente, fosse igual para todos. Contudo, a insensibilidade demonstrada pelo cônsul também é um indicativo da desumanização dos setores burocráticos, que tratam pessoas como números sem considerar suas necessidades e sempre se colocando em posição de superioridade.

Retornando à questão do riso, além o aspecto risível resultante da incompreensão entre o cônsul e a protagonista, a comicidade permite uma subversão destas ordens hierárquicas, uma vez que o objeto risível poderia ser tanto a posição/postura aristocrática de Dona Victória quanto as atitudes pedantes do cônsul, representando, em uma esfera micro, a pretensa soberania dos EUA. O que se desvela no final da breve narrativa é a subversão do "poderio" estadunidense, ao enviar para a casa de Dona Victória o visto, tornando-se, assim, alvo da derrisão.

\section{Encruzilhadas interpretativas: autora e personagem, mulheres cabo-verdianas}

Ondina Maria Duarte Fonseca Rodrigues Ferreira, além de ter vários sobrenomes como a personagem de Dona Victória, também nutre profundo apreço pela Ilha do Fogo, apesar de ter nascido a bordo de um paquete português saído de Mindelo, na Ilha de São Vicente, com destino a Lisboa. Ondina Ferreira é atualmente professora universitária 
aposentada e possui importante atuação política e literária ${ }^{12}$, tendo sido diretora e coordenadora de revistas e suplementos literários em jornais. Ainda exerceu o cargo de Diretora Executiva do Instituto Internacional da Língua Portuguesa entre 2001 e 2004, atuou como Ministra da Cultura e da Tutela da Comunicação Social em 1991/2001 e foi vice-presidente da Assembleia Nacional ${ }^{13}$.

O livro, lançado em 2010, no qual se encontra o conto "O visto", intitula-se Contos com lavas, numa alusão ao vulcão em atividade localizado na Ilha do Fogo ${ }^{14}$. É nesta ilha que todas as breves narrativas se situam geograficamente.

No que tange às questões femininas, em seu artigo intitulado Outras Vozes: Women's Writings in Lusophone Africa (2008) Isabel Fêo e Kathleen Sheldon pontuam que o PAIGC (Partido Africano da Independência da Guiné e Cabo Verde) deu bastante proeminência ao papel das mulheres como educadoras e ativistas políticas nas lutas pela independência, ainda que prevalentemente em termos discursivos ${ }^{15}$.

O supracitado artigo nos fornece contribuições para uma compreensão panorâmica do papel social da mulher em Cabo Verde. Sheldon e Fêo (2008, p. 429) enumeram mulheres cabo-verdianas com destacada atuação social, política e literária como Fátima Bettencourt, Dina Salústio e Vera Duarte (esta, a primeira mulher magistrada a ser indicada para a Suprema Corte em 1990).

Sheldon e Fêo (2008, p. 431-432) indicam, ainda, que a escravização teve consequências devastadoras para as mulheres africanas, uma vez que mulheres brancas representavam uma insignificante minoria no percurso da história colonial e as negras, escravizadas ou libertas, tornaram-se alvos vulneráveis aos ataques sexuais dos senhores europeus. As pesquisas de Elisa Andrade citadas no texto (Ibidem) abordam as formas com as quais as estruturas patriarcais herdadas do colonialismo exerceram influência nas

\footnotetext{
${ }^{12}$ A autora também publica sob o pseudônimo de Camila Montrond, hipoteticamente em alguma alusão ao francês Armand Montrond.

${ }^{13}$ Fontes: http://www.manduco.net/apps/blog/show/873856-alupec-ondina-ferreira-jorge-brito-plagiohttp://iilp.cplp.org/iilp-exdiretores.html. Acessados em: 02. fev. 2015.

${ }^{14}$ Figura que, por sinal, é a ilustração da capa.

15 Em artigo intitulado "O estado da arte dos estudos de gênero na Guiné-Bissau: uma abordagem preliminar", Patrícia Gomes (2015) tece análises sobre os papeis exercidos pelas mulheres nas lutas de libertação da Guiné-Bissau e Cabo Verde. Dentre outros apontamentos, a pesquisadora assevera que as mulheres atuaram em diversos programas de implementação educacional, todavia, suas funções ainda estavam restritas aos campos considerados "tipicamente femininos" como educação, saúde, transporte e preparação de alimentos (GOMES, 2015, p. 174). Mesmo com uma visão de gênero ainda limitada como essa, um dos relatórios sobre a situação feminina em 1972 atesta que as mulheres ocupavam todos os níveis das atividades do Partido [PAIGC]. A participação feminina se dava tanto nos setores básicos, quanto nos altos comandos, ao lado dos homens (Ibidem). Observa-se que, apesar de tais medidas, a desigualdade de gênero não foi solucionada e as lutas femininas persistiram para além dos combates independentistas do PAIGC, que ainda preservava em suas bases e nas bases do Estado estruturas de segmentação.
}

Revista Crioula USP, $\mathrm{n}^{\circ}$ 17, junho de2016 
condições das mulheres na África de língua portuguesa no período pós-colonial. Nesses estudos, Sheldon e Fêo (Ibidem), a partir de Elisa Andrade, destacam que o colonialismo e a demografia contribuíram para a formação de uma sociedade marcada por relações interpessoais nas quais família, status e amizades continuaram ligadas ao poder.

Essa pontuação nos auxilia na compreensão da representação social da personagem Dona Victória e sua persistência na repetição de símbolos de um passado colonial, ainda que isto possa sinalizar para uma ruptura do modelo de dominância masculina, visto que, com a incapacidade de seus irmãos mais velhos na gerência dos bens familiares, ela assume opapel de administradora, casa-se para manter seu espólio e seu marido não aparenta ser a nova figura de comando na casa.

Desta forma, vale ressalvar que a personagem Dona Victória, criada por Ondina Ferreira, mesmo perpetuando algumas ideologias do colonialismo, apresenta rupturas significativas ao não se submeter ao modelo patriarcal: filha codê (caçula) que administra as posses da família, casou-se tarde porque lhe conveio e seu marido não possui o poder efetivo. A própria visita aos EUA era um acordo e não uma ordem unilateral. A insubordinação cômica em relação à desconfiança do cônsul e seu menosprezo pela "soberania" estadunidense também rompem com a subserviência e o culto da "americanização", demonstrando a valorização de sua trajetória e das cultura locais.

\section{REFERÊNCIAS}

ANJOS, José Carlos Gomes dos. Intelectuais, literatura e poder em Cabo Verde: lutas de definição da identidade nacional. Porto Alegre: Ed. UFRGS, 2006.

BATALHA, Luís. "A elite portuguesa-cabo-verdiana: ascensão e queda de um grupo colonial intermediário". In: CARVALHO, Clara; CABRAL, João de Pina (Coord.). A persistência da História. Passado e contemporaneidade em África. LISBOA: Imprensa de Ciências Sociais, 2004.

FERNANDES, Gabriel. A diluição da África: uma interpretação da saga identitária caboverdiana no panorama político (pós)colonial. Florianópolis: Ed. UFSC, 2002.

FERREIRA, Ondina. "O visto". In: Contos com Lavas. Cabo Verde: Edição da Autora, 2010.

GOMES, Patrícia Godinho. O estado da arte dos estudos de gênero na Guiné-Bissau: uma abordagem preliminar. Outros Tempos, vol. 12, n.19, 2015 p. 168-189. Disponível em: $<$ http://www.outrostempos.uema.br/OJS/index.php/outros_tempos_uema/article/view/4 58>. Acesso: 13 jul. 2015.

GOVERNO de Cabo Verde. Página Oficial do Governo de Cabo Verde. Disponível em: $<$ http://www.governo.cv/>. Acesso em: 02 jan. 2015. 
GUIMARÃES, Terena Thomassim. Claridade e Certeza na Hora di Bai. Disponível em: $<$ http://www.wwlivros.com.br/IIjornadaestlit/artigos/port_bras/THOMASSIMTeren aGuimaraes.pdf >. Acesso em: 02 jan. 2015.

LOPES FILHO, João. Contribuição para o estudo da cultura cabo-verdiana. Lisboa: Biblioteca Ulmeiro n. 15, 1983.

SHELDON, Kathleen; RODRIGUES, Isabel P. B. Fêo. Outras Vozes: Women's Writings in Lusophone Africa. In: African and Asian Studies, n. 7, 2008, p. 423-445.

TURISMO Cabo Verde. Site Oficial. Disponível em: <http://www.turismo.cv/fogo>. Acesso em: 02 jan. 2015. 